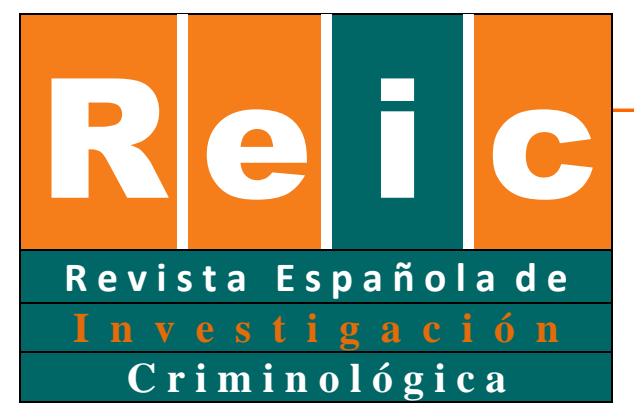

Martí et al.

\title{
Fuentes de datos para la investigación criminológica en el ámbito penitenciario en España
}

\section{Data sources for criminological research on Spanish prisons}

\author{
Recibido 26 febrero 2021/ Aceptado 6 julio 2021
}

\begin{abstract}
Marta Martí1
Universitat Oberta de Catalunya

Cristina Güierri

Universidad de Málaga

Albert Pedrosa

Universitat Autònoma de Barcelona
\end{abstract}

\section{RESUMEN}

El análisis criminológico de la práctica penitenciaria requiere disponer de información sobre su funcionamiento. Este artículo repasa las fuentes de datos cuantitativos existentes sobre la actividad del sistema penitenciario español, centrándose tanto en la información publicada y disponible como en las posibilidades de acceso para la obtención de datos adicionales, oficiales y no oficiales, mediante los portales de transparencia y la investigación empírica en prisión. Respecto a las fuentes oficiales, se detalla qué cuestiones nos permiten estudiar y las limitaciones que presentan. Asimismo, se expone cómo obtener datos no oficiales mediante la realización de encuestas en prisión, desarrollando el procedimiento a seguir y los principales retos. Este artículo concluye que, a pesar de que el acceso a los datos sobre la práctica penitenciaria en España ha mejorado en los últimos años, todavía existen numerosos problemas con los datos oficiales, especialmente relacionados con el contenido, la

${ }^{1}$ La correspondencia debe dirigirse a Marta Martí Barrachina al correo electrónico: $\underline{\text { mmartibarr@uoc.edu }}$

Revista Española de Investigación Criminológica

Artículo 2, Volumen 19 (2) (2021)

https://doi.org/10.46381/reic.v19i2.515

www.criminologia.net

ISSN: 1696-9219 
manejabilidad y el formato de los datos proporcionados. Por ello, al final del artículo se presentan una serie de recomendaciones a la Administración penitenciaria en aras de mejorar el acceso a la información.

Palabras clave: investigación cuantitativa; prisiones; fuentes de datos; acceso a la información; encuestas.

\begin{abstract}
The criminological analysis of prisons requires having information about how they function. This article reviews the existing quantitative data sources on the activity of the Spanish penitentiary system, focusing both on available published official data and on the possibility of obtaining additional information in the form of both official and unofficial data, through freedom of information requests and empirical research in prisons. Regarding official sources, we detail the questions these sources allow us to study and the limitations they present. Likewise, we explain the procedures for obtaining unofficial data by conducting surveys in prison, and the challenges that might arise. This article concludes that, although in recent years access to data about prison practice in Spain has improved, there are still numerous problems with official data, especially regarding the content, manageability, and format of the data provided. For this reason, this paper finishes by presenting a series of recommendations through which the Prison Administration could improve access to relevant information for prison researchers.
\end{abstract}

Key words: Quantitative research; prisons; data sources; access to information; surveys.

\title{
1. Introducción
}

El estudio criminológico de la prisión se ha centrado principalmente en tres cuestiones: en qué medida las sociedades actuales recurren a la pena de prisión, a quién se encarcela y cómo es la vida en los centros penitenciarios. Para realizar este análisis criminológico desde un enfoque cuantitativo es preciso disponer de estadísticas penitenciarias, es decir, información numérica que describa los elementos y circunstancias relacionadas con el cumplimiento de la pena de prisión, como el número de personas encarceladas, sus características sociodemográficas y penitenciarias o la cantidad de incidentes violentos que ocurren en las prisiones.

Esta información puede obtenerse de fuentes de datos oficiales, cuando provienen de los propios poderes públicos, o no oficiales, si provienen de otro tipo de fuentes. En el ámbito de las prisiones españolas, la principal fuente oficial son las Administraciones penitenciarias,

\section{Revista Española de Investigación Criminológica}

Artículo 2, Volumen 19 (2) (2021)

https://doi.org/10.46381/reic.v19i2.515

Www.criminologia.net

ISSN: 1696-9219 
esto es, la Secretaría General de Instituciones Penitenciarias (SGIP) en la Administración General del Estado (AGE) y la Secretaría de Mesures Penals, Reinserció i Atenció a la Víctima (SMPRAV) en Cataluña. Las Administraciones penitenciarias cuentan con numerosos datos sobre la práctica penitenciaria y algunos de ellos se publican periódicamente en sus páginas webs o en sus anuarios. No obstante, la realidad es que la mayor parte de la información de la que disponen no es publicada, si bien es posible solicitarla mediante los portales de transparencia. Por otra parte, en ocasiones necesitamos obtener información distinta de la que recoge la Administración, de manera que los investigadores deben obtenerla por sí mismos mediante una investigación empírica, en cuyo caso hablamos de fuentes no oficiales.

A pesar de las diferentes posibilidades referidas, el acceso a la información sobre las prisiones españolas no es sencillo, ya que existen numerosos obstáculos, como la no publicidad de algunos datos, la escasa manejabilidad de algunas plataformas o la negativa de la Administración a compartir cierta información, que dificultan la investigación criminológica sobre el sistema penitenciario.

Este artículo tiene por objetivo orientar al lector sobre las fuentes de datos cuantitativos en el ámbito penitenciario disponibles en España, destacando sus características y limitaciones, y proveyendo consejos para su obtención y uso. En primer lugar, presentamos una síntesis de las fuentes de datos penitenciarios oficiales publicados en España. En segundo lugar, explicamos el proceso mediante el cual se pueden obtener estos datos oficiales cuando no son públicos, a través de los portales de transparencia. En tercer lugar, reflexionamos sobre aspectos a tener en cuenta para la obtención de datos no oficiales mediante la realización de encuestas en prisión. Por último, concluimos con algunas propuestas para mejorar el acceso a la información sobre la realidad penitenciaria en España. 


\section{Fuentes oficiales I: Información publicada por las Administraciones penitenciarias y otras instituciones}

En este primer apartado explicamos las principales fuentes de información sobre la realidad penitenciaria que distintos organismos oficiales ponen a nuestra disposición.

\section{Tabla 1}

Síntesis de las principales fuentes de datos oficiales

\begin{tabular}{|llc|}
\hline Administración General del Estado & & \\
\hline $\begin{array}{l}\text { Estadística Penitenciaria } \\
\text { Anuarios Estadísticos: Instituciones Penitenciarias (Información } \\
\text { estadística en formato reutilizable) } \\
\text { Informes Generales SGIP }\end{array}$ & SGIP & $\underline{\text { Enlace }}$ \\
\hline Administerio del Interior & $\underline{\text { Enlace }}$ \\
\hline $\begin{array}{l}\text { Descriptors Estadístics Serveis Penitenciaris } \\
\text { Estadístiques - Serveis Penitenciaris }\end{array}$ & SGIP & $\underline{\text { Enlace }}$ \\
Dades Obertes - Presons & SMPRAV & $\underline{\text { Enlace }}$ \\
\hline Otros & Dept. de Justícia & $\underline{\text { Enlace }}$ \\
\hline $\begin{array}{l}\text { Informes Anuales del Mecanismo Nacional de Prevención de la la } \\
\text { Tortura }\end{array}$ & CEJFE & Defensor del Pueblo \\
SPACE I Annual Reports & Consejo de Europa & $\underline{\text { Enlace }}$ \\
Eurostat - Crime and criminal justice & Comisión Europea & $\underline{\text { Enlace }}$ \\
\hline
\end{tabular}

Fuente: Elaboración propia

\subsection{Administración General del Estado}

a) Estadística Penitenciaria (SGIP)

En el portal de la SGIP encontramos información general sobre la población reclusa en España. El portal nos permite conocer el total de población encarcelada según sexo, grupo de edad, nacionalidad, situación procesal-penal, grado de tratamiento, tipología delictiva y 
comunidad autónoma. Dispone de datos desde 1990 hasta la actualidad y permite diferenciar entre "Total Nacional”, “Administración General del Estado" y "C.A. de Cataluña". 2

\section{Figura 1}

Interfaz del portal Estadística Penitenciaria de la SGIP

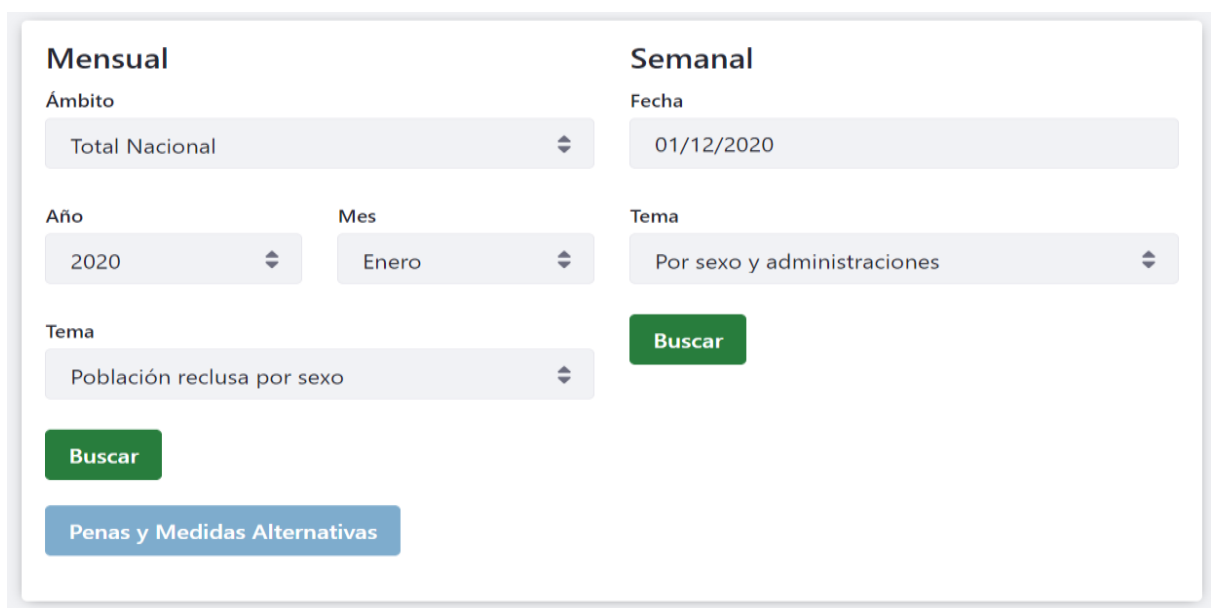

Fuente: Página web SGIP.

Un problema importante de esta fuente es su escasa manejabilidad, ya que no permite cruzar datos ni facilita la elaboración de series temporales. A diferencia del INE, donde se pueden seleccionar las variables deseadas y los años de interés, este portal únicamente permite consultar las categorías predefinidas (las únicas variables ya cruzadas son sexo, situación procesal-penal y grupo de edad, por una parte, y sexo y nacionalidad por otra) y para obtener series temporales es necesario ir seleccionando los años uno a uno y copiar manualmente los datos (es decir, no hay forma de obtener una sola tabla sobre una variable de interés como, por ejemplo, la población reclusa según el sexo para diferentes años). Incluso una cuestión tan simple como conocer el porcentaje de población penitenciaria extranjera resulta laborioso, pues únicamente se proporciona información de la población penitenciaria extranjera sin relacionarla con la total y es necesario consultar por separado el dato de población general para poder efectuar el cálculo. Además, desde mayo de 2020 el

${ }^{2}$ Información también disponible (desde 2006) en formato Excel en la página web del Consejo General del Poder Judicial.

Revista Española de Investigación Criminológica

Artículo 2, Volumen 19 (2) (2021)

https://doi.org/10.46381/reic.v19i2.515

www.criminologia.net

ISSN: 1696-9219 
portal solamente permite consultar la estadística mensual mediante la descarga del documento PDF correspondiente al mes seleccionado. Esto facilita la consulta simultánea de todos los datos que ofrece el portal para una misma fecha, pero complica la elaboración de series temporales.

\section{Figura 2}

Ejemplo de resultado obtenido en el portal Estadística Penitenciaria

\begin{tabular}{|ccc|}
\hline $\begin{array}{c}\text { Mensual > enero 2020 > Extranjeros por sexo } \\
\text { DISTRIBUCIÓN DE LA POBLACIÓN RECLUSA EXTRANJERA, POR SEXO }\end{array}$ & $\%$ \\
Género & Total & \\
Hombres & 15.187 & 92,51 \\
Mujeres & 1.230 & 7,49 \\
Total & 16.417 & 100 \\
\hline
\end{tabular}

Fuente: Página web SGIP.

Otro problema de este portal, común en todas las estadísticas de la AGE, es que no suelen detallar información sobre las categorías que se emplean, lo que en ocasiones genera confusión a la hora de interpretar los datos. Por ejemplo, a veces no se indica la población de referencia de los datos y puede plantearse la duda de si estos se refieren al total de la población reclusa o solo a la penada.

Un último problema es la escasa información disponible, ya que solo nos permite conocer unas pocas características sociodemográficas, penales y penitenciarias de la población reclusa. En este sentido, los Anuarios Estadísticos del Ministerio del Interior y los Informes Generales de la SGIP añaden nueva información.

b) Anuario Estadístico del Ministerio del Interior

El Anuario Estadístico del Ministerio del Interior contiene un capítulo dedicado a Instituciones Penitenciarias, el cual presenta, a grandes rasgos, las mismas categorías de 
información que el portal de Estadística Penitenciaria de la SGIP, aunque algo más detallada, tal y como puede comprobarse en la Figura 3.

\section{Figura 3}

Índice de tablas sobre Instituciones Penitenciarias en "formato reutilizable"

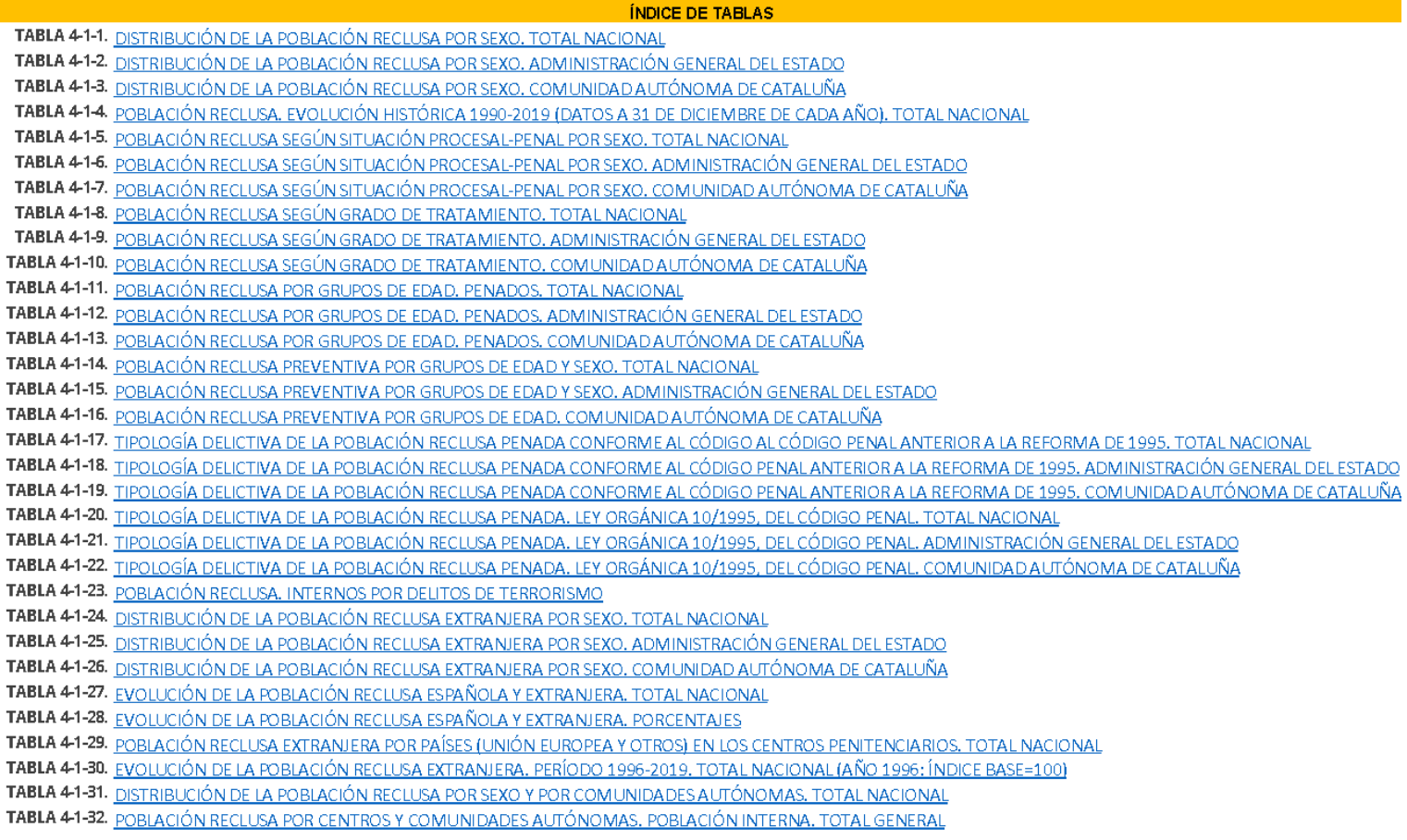

Fuente: Anuario Estadístico del Ministerio del Interior 2019.

Uno de los puntos fuertes de estos datos es que desde 2012 también se ofrecen en lo que el Ministerio del Interior denomina "formato reutilizable", es decir, es posible descargar un libro de Excel con las tablas de datos que contiene el anuario, lo cual facilita la tarea de trabajar con ellos.

No obstante, la información que nos proporcionan sigue siendo bastante limitada. Esta es mucho más rica en los Informes Generales que publica anualmente la SGIP.

\section{c) Informes Generales de Instituciones Penitenciarias}

La SGIP elabora anualmente un Informe General que añade información estadística detallada sobre numerosas cuestiones, desde la clasificación inicial de los penados hasta las cifras

Revista Española de Investigación Criminológica

Artículo 2, Volumen 19 (2) (2021)

https://doi.org/10.46381/reic.v19i2.515

www.criminologia.net

ISSN: 1696-9219 
relativas a los programas de tratamiento impartidos, pasando por la concesión de permisos de salida o los datos epidemiológicos sobre la salud de las personas presas. En la Tabla I del Anexo detallamos los distintos tipos de información que proporcionan estos informes, agrupados por categorías.

Estos Informes Generales contienen información muy rica pero, a causa de su formato (un archivo PDF de cientos de páginas), siguen presentando problemas de manejabilidad, y extraer la información que contienen resulta laborioso, especialmente cuando queremos elaborar series temporales. Asimismo, no todos los datos de interés se encuentran en tablas, por lo que resulta necesario leer los extensos capítulos del informe para averiguar si el dato que nos interesa está reflejado en el texto. En este sentido, consideramos que sería positivo que la SGIP también ofreciera los datos en "formato reutilizable".

Un último problema de los Informes Generales de Instituciones Penitenciarias, común a los Anuarios Estadísticos del Ministerio del Interior, es la lentitud con la que son actualizados. A fecha de envío de este artículo (febrero del 2021), el Informe General más reciente es el de 2018 y acaban de ser publicados los datos del Anuario Estadístico 2019.

\subsection{Administración Penitenciaria Catalana}

\section{a) Descriptors Estadístics de Serveis Penitenciaris i Rehabilitació (SMPRAV)}

Descriptors Estadístics de Serveis Penitenciaris i Rehabilitació es un portal estadístico que nos ofrece información (en catalán) específica sobre las prisiones gestionadas por la Generalitat de Catalunya. Este portal se actualiza mensualmente y agrupa los datos proporcionados en catorce categorías distintas, tal y como puede constatarse en la Tabla II del Anexo.

La información de este portal es bastante más rica que la del Portal Estadístico de la SGIP y más manejable que la de los Informes Generales de Instituciones Penitenciarias: la navegación por las categorías y subcategorías es sencilla y la información aparece representada simultáneamente en una tabla y una gráfica (véase la Figura 4). Los datos suelen presentarse mensualmente y comparando el año en curso con el año anterior. Además, la mayoría de categorías ofrecen la posibilidad de consultar el "Histórico" de los 10 últimos

Revista Española de Investigación Criminológica

Artículo 2, Volumen 19 (2) (2021)

https://doi.org/10.46381/reic.v19i2.515

www.criminologia.net

ISSN: 1696-9219 
años y desagregar muchos de los indicadores según el perfil sociodemográfico de los reclusos.

\section{Figura 4}

Interfaz del portal Descriptors Estadístics de Serveis Penitenciaris

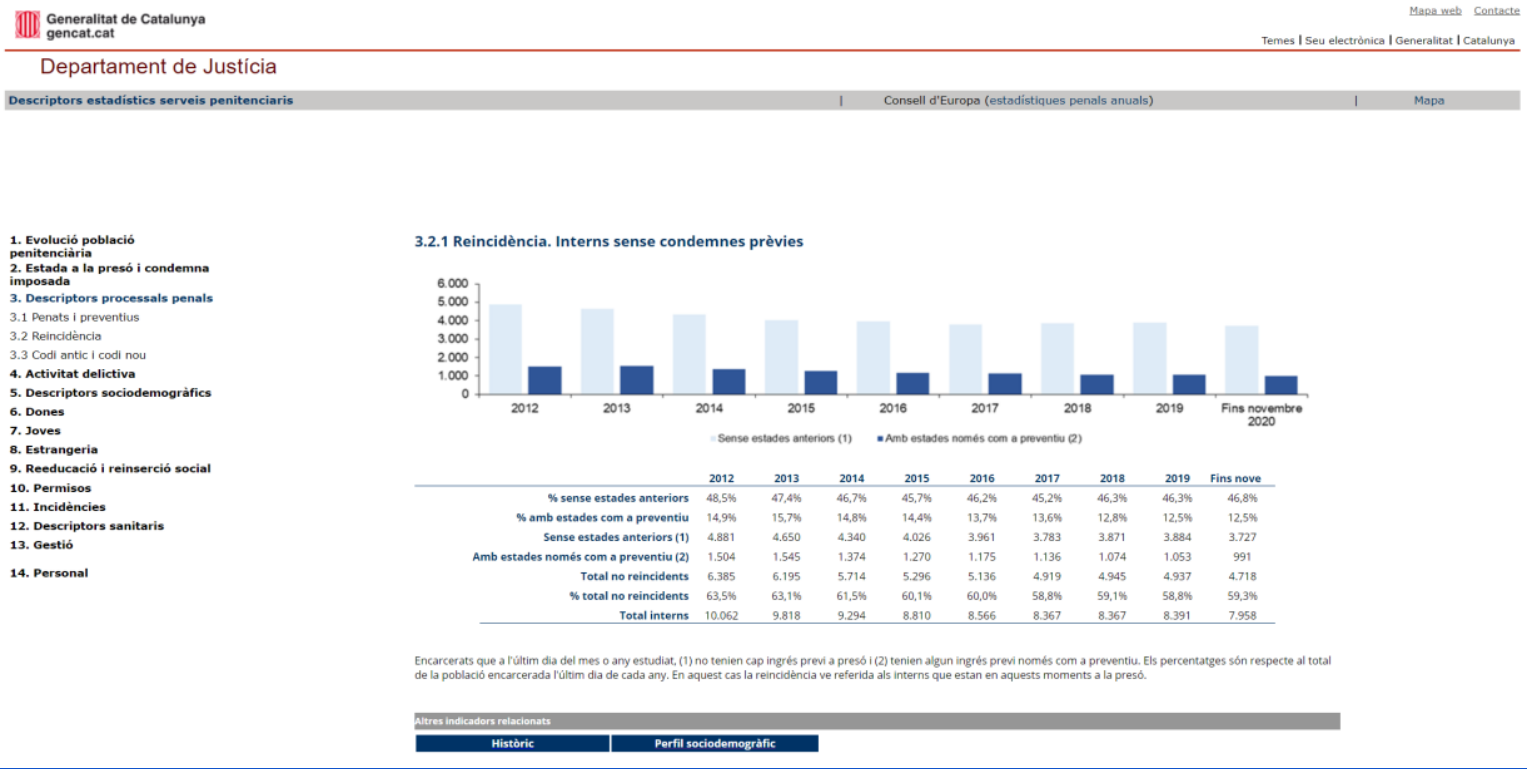

Fuente: SMPRAV.

Otro aspecto positivo de esta fuente es que describe qué se está contabilizando en las categorías que emplea, tal y como se puede observar en la parte inferior de la figura anterior.

A pesar de la mejor usabilidad de este portal en comparación con el de la SGIP, esta página no está exenta de problemas: la información es difícil de copiar para trabajar con ella y nuestra capacidad de análisis sigue estando restringida a las categorías predefinidas en el propio portal. Además, a medida que el portal se actualiza, elimina los registros anteriores a 10 años, es decir, únicamente nos permite consultar la evolución de los indicadores en la última década.

Finalmente, queremos señalar que, además de este portal, el Departament de Justícia de la Generalitat de Catalunya también publica en formato Excel "Estadístiques - Serveis Penitenciaris", una base de datos que contiene series temporales (2010-2019) para los principales indicadores del sistema penitenciario (p. ej., población encarcelada, estancia

Revista Española de Investigación Criminológica 
media en prisión o incidentes regimentales ocurridos), las características de la población reclusa (p. ej., sociodemográficas, penales o de participación en programas de rehabilitación y actividades laborales) o la plantilla y la capacidad del sistema penitenciario.

b) Dades Obertes: Presons (Departament de Justícia)

Todas las fuentes de datos oficiales presentadas hasta el momento contienen indicadores que nos resultan útiles para hacernos una idea de la situación actual del sistema penitenciario. Sin embargo, el hecho de que la información se nos proporcione siempre de forma agregada impide realizar análisis más profundos en los que explorar cuestiones como la relación entre las características sociodemográficas, penales y penitenciarias de los individuos con su participación en incidentes regimentales o su progresión penitenciaria.

A este respecto, queremos destacar una buena práctica del Centro de Estudios Jurídicos y Formación Especializada (en adelante, CEJFE) del Departament de Justícia de Catalunya, el cual publica en acceso abierto algunas de las bases de datos que emplea en sus estudios. En lo relativo al ámbito penitenciario, han publicado investigaciones sobre tres temas: libertad condicional (p. ej., "La libertad condicional en Cataluña”), reincidencia (p. ej., "Tasa de reincidencia penitenciaria 2014") y extranjería ("Extranjeros en las cárceles catalanas"). Para cada investigación, se proporcionan los correspondientes informes, la ficha técnica, la base de datos y la descripción de las variables y su codificación.

\subsection{Otros}

Además de la Administración penitenciaria, existen otras fuentes de carácter institucional que nos ofrecen información acerca del sistema penitenciario español.

a) Informes Anuales del Mecanismo Nacional de Prevención de la Tortura (Defensor del Pueblo)

Los Informes Anuales que el Defensor del Pueblo elabora en sus actuaciones como Mecanismo Nacional de Prevención de la Tortura en los centros penitenciarios añaden poca información respecto a la que podemos encontrar en los portales estadísticos antes mencionados, pero los datos adicionales que contienen son sobre temáticas de especial 
relevancia. ${ }^{3}$ Concretamente, el anexo "Datos estadísticos sobre la privación de libertad de larga duración - Centros Penitenciarios" contiene información detallada según centro penitenciario de aspectos como el uso del primer grado y el aislamiento, de las sujeciones mecánicas, de los fallecimientos según tipología, de la asistencia sanitaria a la población reclusa o la atención a personas con problemas de salud mental.

b) SPACE I Annual Reports (Consejo de Europa)

El Consejo de Europa publica anualmente en colaboración con la Université de Lausanne (Suiza) informes con las estadísticas penales de los Estados Miembros. Los informes "SPACE I" se centran en las medidas privativas de libertad, y los datos proporcionados se dividen en seis bloques: a) Características de los internos; b) Capacidad de las instituciones penales; c) Personal penitenciario; d) Altas y bajas; e) Duración del encarcelamiento; y f) Coste del encarcelamiento (para ampliar, véase Aebi \& Tiago, 2020).

A pesar de que gran parte de esta información está disponible en las fuentes que hemos explicado anteriormente, la gran ventaja que proporciona SPACE I es que permite comparar los datos de España (y de la Administración General del Estado y Cataluña) con otros países del Consejo de Europa. Adicionalmente, cabe destacar el detalle con el que cada una de las categorías empleadas es descrita con el fin de garantizar su comparación.

Aunque los puntos fuertes de SPACE I son muy positivos, surge de nuevo el problema de la manejabilidad: los datos solo se nos ofrecen como informe y no es posible descargar las tablas. Asimismo, si queremos estudiar series temporales basadas en estos datos deberemos descargar el informe de cada año y elaborarlas manualmente.

\section{c) Eurostat - Crime and Criminal Justice (Comisión Europea)}

Finalmente, Eurostat, el portal estadístico de la Comisión Europea, también incluye estadísticas penitenciarias que posibilitan comparar los países de la Unión Europea. Concretamente, ofrece información sobre: a) Presos según tipología delictiva y sexo; b) Capacidad y nivel de ocupación de las prisiones; c) Presos según edad y sexo; d) Presos según nacionalidad; y e) Presos según situación procesal-penal.

\footnotetext{
${ }^{3}$ En Cataluña esta función también la realiza el Síndic de Greuges, pero sus informes son cualitativos y no aportan información estadística.

Revista Española de Investigación Criminológica

Artículo 2, Volumen 19 (2) (2021)

https://doi.org/10.46381/reic.v19i2.515

Www.criminologia.net

ISSN: 1696-9219
} 


\section{Figura 5}

Datos disponibles en Eurostat sobre "Prisión y características de los presos"

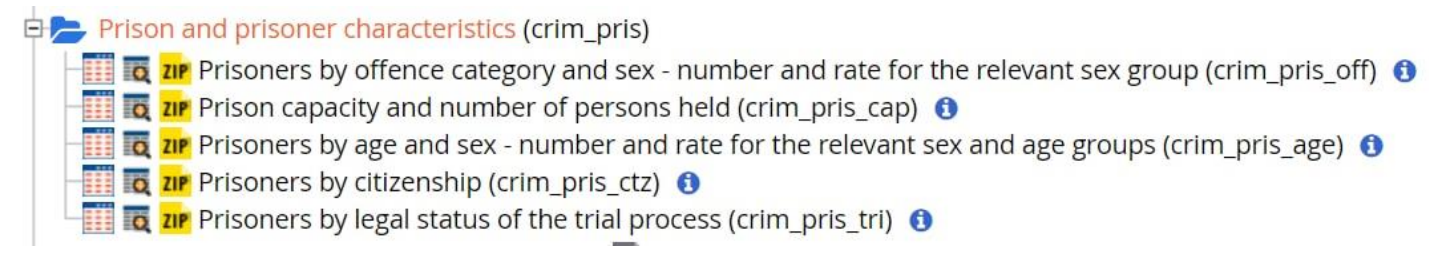

Fuente: Eurostat.

Frente a SPACE I, Eurostat destaca por ofrecer series temporales y la posibilidad de descargar los datos en diversos formatos. En contrapartida, las categorías de información que se ponen a nuestra disposición son mucho más limitadas y no ofrece datos desagregados para la AGE y Cataluña.

\subsection{Síntesis}

Con la información que publican las fuentes oficiales e institucionales reseñadas, es posible analizar cuantitativamente cuestiones como la evolución del encarcelamiento (Cid, 2020), las condiciones materiales en las que este se da (González, 2012), cómo se ejecuta el régimen abierto (Cutiño, 2015) o la situación específica de mujeres y extranjeros (García-España, 2012).

A pesar de ello, siguen existiendo numerosas limitaciones compartidas por todas estas fuentes. En primer lugar, de contenido: no disponemos de información sobre cuestiones relevantes como el nivel socioeconómico o la frecuencia de las comunicaciones (ambos aspectos que la Administración conoce, pues el Informe General de IIPP proporciona este dato en relación con los mayores de 70 años) o el origen étnico de los reclusos (no disponemos de datos oficiales, por ejemplo, sobre cuánta población gitana hay en las cárceles españolas).

En segundo lugar, hay un problema de manejabilidad, pues en general resulta muy laborioso recopilar los datos para la elaboración de tablas y gráficos u obtener series temporales para analizar la evolución de los datos disponibles. Además, únicamente se 
pueden analizar las categorías predefinidas. En este sentido, en las fuentes nacionales, la tipología delictiva se basa en la categorización del Código Penal (p. ej., "Contra el patrimonio y el orden socioeconómico") en vez de desagregarse por delitos concretos (p. ej., robo con violencia), lo cual mejoraría la comparabilidad con los datos policiales o con otros países. Otra problemática frecuente es que no se permite elegir cómo cruzar las variables (p. ej., población extranjera según grado de tratamiento).

Por último, exceptuando los Datos Abiertos sobre prisiones del CEJFE, la información es siempre agregada, en vez de según individuo o centro penitenciario, y ello limita considerablemente las posibilidades de análisis.

\section{Fuentes oficiales II: Obtención de datos oficiales no publicados}

En el apartado anterior hemos constatado que los datos oficiales publicados en España presentan numerosas limitaciones. Sin embargo, la Administración penitenciaria cuenta con un gran volumen de datos adicionales, generados mediante la propia práctica penitenciaria, que no publica por distintos motivos: por su enorme volumen, porque hacen referencia a información considerada "sensible", o por miedo de que su conocimiento ponga en evidencia aspectos críticos de la práctica penitenciaria. No obstante, se puede acceder a esta información mediante dos vías: pidiéndola a través de los portales de transparencia o consultando directamente las bases de datos de la Administración, previo permiso. A continuación, describimos cómo.

\subsection{Los portales de transparencia}

Durante años la única información pública sobre el sistema penitenciario español era la que la propia Administración quería que se conociera. Sin embargo, esta situación mejoró a raíz de la entrada en vigor de la Ley 19/2013, de 9 de diciembre, de Transparencia, Acceso a la Información Pública y Buen Gobierno, la cual afecta a todas las instituciones y Administraciones españolas. Además de obligar a las instituciones a hacer publicidad activa sobre su actividad y gestión, esta ley creó un Portal de la Transparencia estatal para facilitar 
el acceso de los ciudadanos a la información pública, ${ }^{4}$ incluyendo la información sobre la actividad penitenciaria y la ejecución de las penas de prisión.

No obstante, el artículo 14 prevé algunos límites a este derecho que pueden llevar a la no publicidad, total o parcial, de los datos que sean requeridos. Estos límites son generales $y$, en ocasiones, un tanto ambiguos, pero para el tema que nos ocupa destacan aquellos que hacen referencia a la protección de datos personales. En el ámbito penitenciario, es especialmente importante que el conjunto de los datos solicitados no permita identificar a personas o casos concretos para preservar su intimidad y evitar el etiquetamiento. Ahora bien, esto no debería resultar un impedimento en la mayoría de las ocasiones, puesto que los datos se pueden anonimizar y el artículo 16 establece que pueden tratarse para su acceso parcial si el acceso total afecta la protección de datos personales.

El procedimiento para la solicitud de información es el siguiente: los ciudadanos deben acceder al portal web de transparencia e identificarse mediante un certificado digital autorizado. Una vez identificados, la solicitud debe realizarse en la propia plataforma (o en el documento que el portal proporciona en el caso de Cataluña), indicando la temática, la información que se desea obtener y el medio por el cual se desea recibir (correo postal o electrónico).

Es muy importante que la petición sea lo más específica posible, haciendo referencia a variables concretas, estableciendo el periodo temporal, ámbito territorial y tipo de régimen penitenciario (Figura 6). Por ejemplo, si quisiéramos estudiar el mal comportamiento en las prisiones españolas, no deberíamos simplemente pedir datos acerca del "mal comportamiento", pues las formas de medirlo son muy amplias. Así, es aconsejable solicitar variables concretas como el número de expedientes disciplinarios, las sanciones impuestas y su tipología o el total de personas sancionadas, especificando un límite temporal y todas aquellas variables que vayamos a utilizar en nuestros análisis o que permitan una descripción de nuestros datos (como el género, la nacionalidad o el régimen de vida de la persona

\footnotetext{
${ }^{4}$ Disponible en: https://transparencia.gob.es/. Al amparo de la misma ley, la Generalitat de Catalunya cuenta con su propio portal: http://www.transparenciacatalunya.cat/es/inici/. 
sancionada). A su vez, es importante establecer el formato en el que se desean recibir los datos (Word, Excel...).

\section{Figura 6}

Ejemplo de una petición realizada sobre datos relativos a las personas en medio abierto

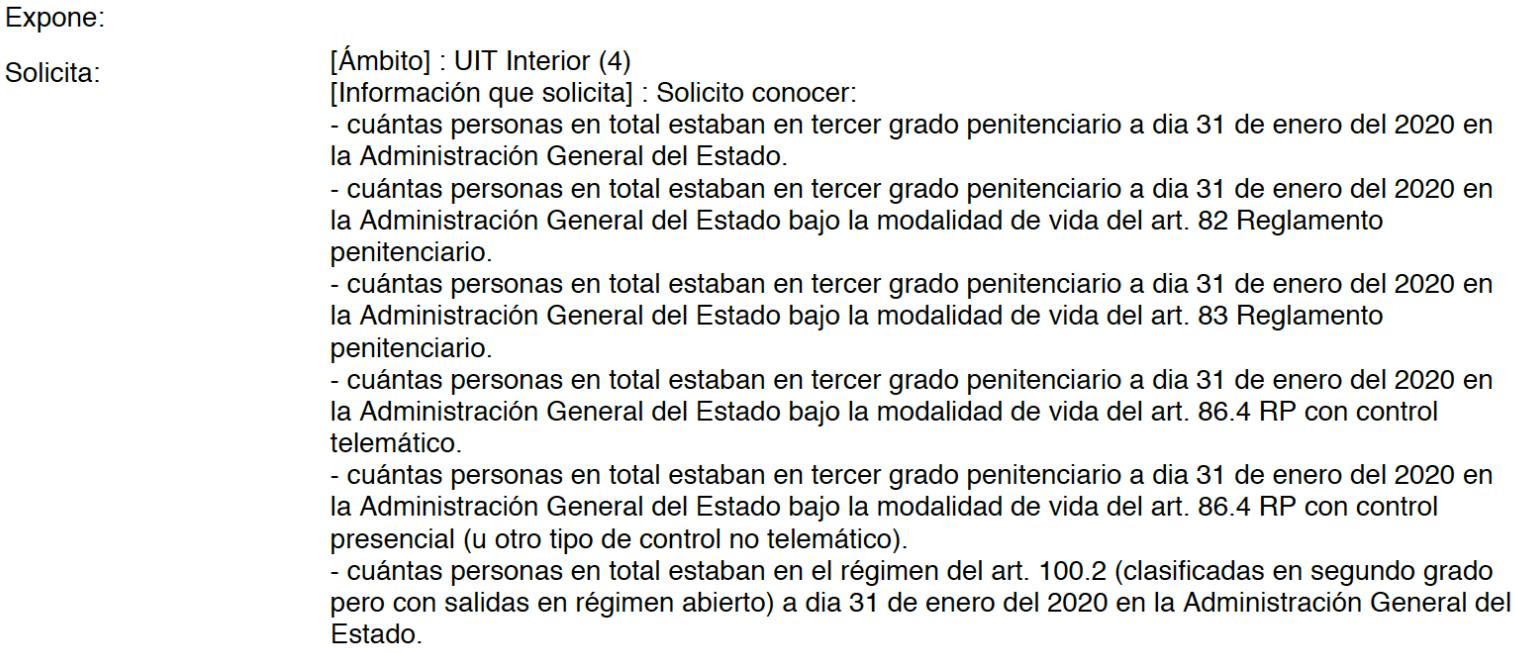

Fuente: Elaboración propia.

La ley prevé un plazo máximo de un mes para que la Administración notifique la aprobación o denegación de la solicitud, con posibilidad de recurso. Una de las causas de inadmisión previstas se refiere al supuesto de que se deba reelaborar la información para su envío. Este supuesto es muy amplio, puesto que en realidad la mayoría de información "en bruto" (recogida directamente por los profesionales o la institución) debe tratarse antes de su envío. Así, este criterio de inadmisión podría convertirse en un cajón de sastre empleado para la denegación de solicitudes, sobre todo, las más complejas. ${ }^{5}$

Finalmente, al realizar una petición de información mediante el portal de transparencia existe el reto de saber qué nos interesa y qué debemos pedir exactamente, ya que la Administración no publica qué tipo de datos tiene a su disposición. Consultar los

${ }^{5}$ Según datos del propio portal, un $12 \%$ de las inadmisiones en 2019 fueron por este motivo.

Revista Española de Investigación Criminológica

Artículo 2, Volumen 19 (2) (2021)

https://doi.org/10.46381/reic.v19i2.515

WWW.criminologia.net

ISSN: $1696-9219$ 
informes oficiales resumidos en el apartado anterior puede ser un buen punto de partida. Así, se pueden pedir aquellos datos publicados en los informes que se deseen analizar con mayor profundidad, ya sea cruzando distintas variables o pidiendo series temporales para un análisis longitudinal. Por ejemplo, si en un informe se publica el porcentaje de personas presas con algún problema de salud mental, se podría realizar una petición de otros indicadores relacionados, como el tipo de afectación o la incidencia de estas problemáticas, añadir variables como el género o la edad, o solicitar los datos para distintos años.

\subsection{Creación de bases de datos desagregados a partir de la solicitud a la Administración}

Las dos Administraciones penitenciarias españolas cuentan con un Sistema Informático Penitenciario (SIP, o SIPC en Cataluña) que almacena toda la información penitenciaria sobre las personas que ingresan en los centros penitenciarios. En el SIP, cada interno tiene su propia ficha, la cual, en el caso de Cataluña, contiene datos sobre: a) la duración y evolución de su condena, incluyendo cambios en su clasificación, obtención de permisos y cambios de centro; b) el Plan Individual de Tratamiento; c) el seguimiento del tratamiento y evaluación del riesgo mediante el protocolo RISCANVI; d) la apertura y resolución de expedientes disciplinarios; y e) el entorno social y familiar de la persona condenada. Aunque la mayor parte de la información es sobre la condena actual (o la última condena si la persona ya ha salido en libertad), puede encontrarse también información sobre condenas anteriores. ${ }^{6}$

Esta información es muy abundante y rica, y al estar desagregada según individuos permite responder a nuevas preguntas. Un ejemplo de investigación mediante el uso de estos datos lo encontramos en el estudio sobre imposición de expedientes disciplinarios por género realizado por Batlle (2020). A través de una petición mediante el portal de transparencia, la autora logró conocer las sanciones según gravedad impuestas por sexo, dato que no encontramos publicado. Para mejorar el análisis sobre las causas de la imposición de sanciones, la autora hizo una petición adicional para acceder a distintas variables individuales

\footnotetext{
${ }^{6}$ La información de las variables que integran el SIP y el SIPC no está publicada. La explicación aquí proporcionada procede de nuestra propia experiencia con el uso del segundo. 
(datos sociodemográficos y de trayectoria delictiva), recibiendo permiso para ello, lo cual le permitió realizar análisis más complejos y relevantes que los que habría podido realizar únicamente con los datos públicos u obtenidos mediante el portal de transparencia.

Por tanto, la información del SIP puede resultar muy útil para la investigación criminológica. Sin embargo, el volumen de información, el hecho de que esta se contenga en fichas individuales, no esté preparada para su uso agregado, y contenga información sensible, dificulta que esta información nos sea proporcionada mediante los portales de transparencia. Por este motivo, es preciso realizar una petición formal a la Administración penitenciaria para consultar estos datos. ${ }^{7}$ Asimismo, aunque obtengamos autorización para crear nuestra propia base de datos, la recolección de los mismos es muy laboriosa, ya que los expedientes de las personas encarceladas deben revisarse uno a uno. Además, por un tema de protección de datos, la recolección de información debe ser realizada in situ en un ordenador provisto por la Administración. Por todo ello, es importante contar de antemano con una adecuada planificación de las variables a recoger.

\section{Datos no oficiales: Investigar en prisión}

En el apartado anterior explicamos que se pueden obtener datos de las bases internas de la Administración penitenciaria. Sin embargo, cuando requerimos información cuantitativa distinta de la recogida por la Administración, solo nos queda tratar de obtenerla nosotros mismos mediante una encuesta, a cuyo proceso y retos dedicamos este último apartado.

En la literatura criminológica española encontramos numerosos ejemplos de trabajos basados en encuestas a la población reclusa, como los de Ríos \& Cabrera (1998) y Gallego et al. (2010), quienes analizaron las condiciones de vida en las prisiones españolas enviando cartas con un cuestionario a más de cuarenta centros penitenciarios; las investigaciones de Rodríguez et al. (2018), Barquín et al. (p. ej., 2019) y Pozo et al. (p. ej., 2020) sobre calidad de vida en prisión; el estudio sobre la vivencia del encarcelamiento y el optimismo al final

\footnotetext{
${ }^{7}$ Véase el procedimiento en la Instrucción 12/2019, sobre investigaciones en el medio penitenciario, para las solicitudes en el ámbito de la AGE. Para Cataluña, recomendamos contactar directamente con el Àrea de Planificació i Projectes Estratègics de la SMPRAV.
}

Revista Española de Investigación Criminológica

Artículo 2, Volumen 19 (2) (2021)

https://doi.org/10.46381/reic.v19i2.515

Www.criminologia.net

ISSN: 1696-9219 
de la condena de Cid et al. (2021); la investigación de Caravaca et al. (2020) sobre la relación entre la reincidencia y salud mental, consumo de drogas y otras variables relacionadas con el tratamiento; y el trabajo de Cuaresma \& Nicolás (p. ej., 2008), quienes utilizaron cuestionarios para medir el efecto de la formación inicial en las actitudes profesionales de los funcionarios penitenciarios de nueva incorporación.

Realizar una encuesta en prisión es una tarea que conlleva importantes retos. Algunos son compartidos con diferentes ámbitos de las ciencias sociales, pero otros tienen mucho que ver con las particularidades de los contextos de encierro. A continuación, con el objetivo de ofrecer recomendaciones a personas que planean realizar sus primeras investigaciones en prisión, exponemos estas dificultades, divididas en cuatro grupos: dificultades de acceso, dificultades de aplicación, dificultades de configuración de la muestra y cuestiones éticas.

\subsection{Dificultades de acceso}

Probablemente el reto principal para realizar una encuesta en prisión es obtener el permiso de la Administración penitenciaria, pues sin esta autorización no se puede acceder a un centro penitenciario y, por lo tanto, es prácticamente imposible realizar una encuesta a una muestra representativa de la población presa. ${ }^{8}$ Para obtener el permiso, debe realizarse una solicitud a la Administración penitenciaria, que generalmente requiere exponer los objetivos y la metodología de la investigación, la muestra a encuestar, el espacio que se solicita utilizar y un cronograma, entre otras cuestiones. ${ }^{9}$ Este proceso de solicitud suele ser largo, porque la Administración puede tardar meses en dar una respuesta y, en ocasiones, pueden solicitarnos cambios en el proyecto que requieren realizar una nueva solicitud (véase Field et al., 2019). Por lo general, los investigadores no disponemos de tanto tiempo (tenemos fechas límites para entregar la tesis doctoral, el proyecto de investigación...) y, en todo caso, la incertidumbre sobre si podremos realizar el trabajo de campo y en qué condiciones es

\footnotetext{
${ }^{8}$ Pueden encontrarse alternativas, como el envío de cuestionarios por correo postal a los centros penitenciarios o encuestar a personas en semilibertad o de permiso, pero estas alternativas no sirven para cualquier investigación y difícilmente nos permitirían alcanzar muestras representativas.

${ }^{9}$ Véase nota al pie número 7.

Revista Española de Investigación Criminológica

Artículo 2, Volumen 19 (2) (2021)

https://doi.org/10.46381/reic.v19i2.515

Www.criminologia.net

ISSN: 1696-9219
} 
desgastante y estresante. Ante esta situación, es recomendable tener siempre un plan alternativo por si no obtenemos el permiso o bien este se retrasa demasiado.

Obtener una respuesta favorable no es una tarea sencilla, pues identificamos, al menos, dos tipos de dificultades. Por un lado, las Administraciones penitenciarias suelen ser reticentes a que personas externas investigadoras tengan acceso al interior de las prisiones (González, 2012) y puedan obtener información que no dé una buena imagen de ellas (véase la reacción de la Administración penitenciaria ante la investigación de Ríos \& Cabrera, 1998). Por otro lado, en las prisiones los movimientos de las personas presas están limitados y vigilados, y las rutinas muy pautadas. La presencia de personas externas a la institución altera esta rutina (Sutton, 2011) y la Administración puede considerar que no dispone de recursos humanos necesarios para atender situaciones de este tipo o que es demasiado riesgoso en términos de seguridad (Field et al., 2019). De hecho, la seguridad no se usa solo para dificultar el contacto de los presos con los investigadores sino también con periodistas o sus propios familiares (p. ej., Güerri et al., 2021).

Para intentar minimizar estos riesgos y reducir las posibilidades de que se nos deniegue el permiso con base en este tipo de argumentos, es recomendable mostrar que somos conscientes de esta cuestión y que tenemos flexibilidad para abordarlas. Por ejemplo, podemos ofrecer ir al centro penitenciario en horario de mañana y tarde durante dos días o solo en horario de mañana durante cuatro días. En definitiva, obtener el acceso a las prisiones es un "proceso de constante negociación" y debemos estar preparados para ello (Beyens et al., 2015, p. 68).

\subsection{Dificultades de aplicación}

Una vez obtenido el permiso, surgen otras dificultades relacionadas con la aplicación de los cuestionarios. Una de ellas consiste en los traslados a los centros penitenciarios, ya que estos suelen ubicarse lejos de los núcleos urbanos y con una disponibilidad muy limitada de transporte público, lo cual implica que disponer de un coche es prácticamente imprescindible en todas las investigaciones de este tipo. 
Por otra parte, deben tenerse presente una serie de dificultades relacionadas con la dinámica interior de las prisiones y el control de la seguridad. Para acceder a los módulos internos, es preciso pasar por los controles de seguridad y cumplir con una serie de normas. Quizás la más relevante para los investigadores es que probablemente no se pueden introducir grabadoras (esta es una de las cuestiones a "negociar" en la solicitud del permiso de acceso) y mucho menos teléfonos móviles. Aunque esto no sea un problema para la realización de encuestas, sí puede serlo si el proyecto incluye técnicas metodológicas cualitativas, como las entrevistas. Aunque puedan parecer dificultades sin importancia, es muy recomendable tenerlas presentes para evitar contratiempos y que el trabajo de campo se desarrolle con tranquilidad.

Por último, las rutinas y horarios que regulan la vida en prisión pueden dificultar la realización de las encuestas. Primero, hay que diseñar la administración de los cuestionarios teniendo en cuenta los horarios y especificidades de cada módulo, y estos detalles generalmente no se conocen hasta el inicio del trabajo de campo. Por eso es importante tener una reunión previa con la dirección del centro para conocer cómo se organiza ese centro penitenciario y, en particular, cada módulo (qué actividades se llevan a cabo, si hay jornadas “extraordinarias" previstas durante esos días, a qué hora está prevista la comida para no interferir en ella...). Segundo, hay que tener presente que moverse por dentro del centro penitenciario es complicado porque en la mayoría de ellos los investigadores deben hacerlo acompañados por el personal de vigilancia, y realizar este acompañamiento implica dejar su puesto durante un rato (que ante las dimensiones de algunas prisiones puede ser considerable).

Es aconsejable que al llegar a cada uno de los módulos hablemos con el funcionario de interior encargado para informarle sobre lo que vamos a hacer, cómo lo vamos a hacer y qué necesitamos, así como preguntarle cómo nuestro trabajo puede afectar el funcionamiento del módulo y cómo podríamos minimizar nuestro impacto. Esta conversación ayuda a que tengamos una mejor organización (podemos anticipar inconvenientes, sabremos a quién tenemos que dirigirnos si tenemos alguna duda o necesitamos ayuda...) y a establecer una mejor relación con el personal, pues como afirman Beyens et al. (2015), obtener un permiso

Revista Española de Investigación Criminológica

Artículo 2, Volumen 19 (2) (2021)

https://doi.org/10.46381/reic.v19i2.515

www.criminologia.net

ISSN: 1696-9219 
formal para acceder a los centros penitenciarios no significa que estos estén preparados para recibir con los brazos abiertos a un investigador curioso. De hecho, existen experiencias en España en las que una parte del personal penitenciario se ha opuesto a una encuesta. ${ }^{10}$

La mayoría de las dificultades comentadas varían según si el formato de administración de la encuesta es la autocumplimentación (es decir, los propios presos leen y contestan las preguntas) o cara a cara (un investigador hace las preguntas y anota las respuestas). El formato de autocumplimentación disminuye considerablemente la duración del trabajo de campo y requiere menos personal investigador, por lo que reduce el coste del estudio y además conlleva un menor impacto en el centro penitenciario. Sin embargo, esta opción tiene algunas desventajas, como la dificultad para participar de las personas analfabetas o que no conocen el idioma, el mayor margen de interpretación de las preguntas por parte de las personas encuestadas y la pérdida de información de tipo cualitativo que se obtiene cuando las encuestas las realizamos los investigadores. Algunos de estos problemas pueden minimizarse si los investigadores están presentes o se administran los cuestionarios cara a cara, ya que los presos pueden hacer preguntas y se puede encuestar a quien no sepa leer y escribir, incluso a personas que no hablen español si el investigador conoce su idioma.

\subsection{Dificultades para configurar la muestra}

En torno a la realización de encuestas en prisión existen otra serie de dificultades que están relacionadas con la configuración de la muestra. Una de ellas consiste en que las personas presas no se asignan a las prisiones de manera aleatoria, sino que las Administraciones penitenciarias, y también concretamente la dirección de cada centro, organizan las prisiones siguiendo varios criterios. Ciertamente, el criterio principal es la ubicación geográfica, pero este no es el único. Por ejemplo, hay prisiones que están destinadas mayoritariamente a personas en situación procesal preventiva y otras tienen más población extranjera porque son el destino principal de personas que no están empadronadas. Además, no todas las prisiones tienen los mismos módulos ni organizan la población reclusa de la misma manera. Todo ello

\footnotetext{
${ }^{10}$ Por ejemplo, véase Ríos y Cabrera (1998) o la circular del Sindicato UGT Presons sobre una encuesta del Síndic de Greuges (Almela, 18 de febrero de 2021).
}

Revista Española de Investigación Criminológica

Artículo 2, Volumen 19 (2) (2021)

https://doi.org/10.46381/reic.v19i2.515

www.criminologia.net

ISSN: 1696-9219 
es importante porque en función del tipo de estudio que estemos haciendo es posible que necesitemos encuestar a un tipo de población reclusa en concreto y no nos sirva cualquier centro penitenciario, o bien porque necesitaremos estratificar la muestra por módulos.

Los investigadores difícilmente podemos conocer de antemano cómo se distribuye la población reclusa en las distintas cárceles de un territorio y mucho menos cómo se organiza internamente cada prisión, ya que esta información no siempre es pública. En estos casos, es recomendable que una vez hayamos obtenido la autorización para llevar a cabo el estudio, tengamos una reunión inicial con la Administración penitenciaria para conocer cómo se organiza y poder seleccionar adecuadamente las prisiones. También es de ayuda reunirse con la dirección del centro penitenciario en el que administraremos encuestas para conocer la configuración del mismo (cuántos módulos hay, de qué tipo son, con cuántas personas...) y determinar qué módulos serán objeto de estudio.

Otra dificultad para configurar la muestra es que para que sea representativa es necesario contar con el listado de internos de cada centro penitenciario (o de los módulos objeto de estudio). Por razones de confidencialidad/privacidad, es posible que no podamos tener el listado completo (es decir, con los nombres y apellidos) fuera del centro penitenciario y, por lo tanto, realizar la selección de la muestra desde nuestros ordenadores. Existen dos posibilidades para solventar este problema: o bien pedimos un listado anonimizado (que tenga el número que se asigna a cada persona presa, para así poder identificar a los seleccionados), o bien pedimos permiso para realizar la selección en un ordenador del propio centro penitenciario. La primera opción entorpece la búsqueda de las personas seleccionadas cuando empecemos a hacer las encuestas, ya que no tendremos sus nombres, mientras que la segunda implica pedir al centro penitenciario que nos preste un ordenador y dedicar parte del tiempo que acudimos al centro para realizar la selección in situ. Ambas opciones nos sirven y, en todo caso, dependerá del centro penitenciario, si bien en nuestra opinión es preferible tratar de obtener el listado con los nombres porque esto facilita el proceso de identificar las personas seleccionadas.

También es frecuente que en el momento de realizar las encuestas algunas de las personas seleccionadas como parte de la muestra no estén disponibles porque han sido

\section{Revista Española de Investigación Criminológica}


trasladadas a otro módulo, están realizando una actividad fuera del mismo, están de permiso, han finalizado la condena o están cumpliendo una sanción de aislamiento, entre otros motivos. Por eso, y porque probablemente muchos rechazarán ser encuestados, es necesario que tengamos preparada una lista de suplentes también preseleccionados aleatoriamente.

Por último, existen dificultades para capturar todos los perfiles de la población presa. Por una parte, las personas que no conocen el idioma o son analfabetas no pueden participar en las encuestas que se administran de forma autocumplimentada. Si los investigadores están en el centro penitenciario podrían llevar a cabo algunas encuestas de forma personal para remediar este problema, si bien es más probable que la barrera idiomática no pueda superarse en muchos casos. Por otra parte, incluir en la muestra a personas que están en aislamiento es muy complicado porque los controles de seguridad son más restrictivos, por lo que es posible que, si la naturaleza del estudio lo permite, nos convenga centrarnos solamente en la población que está en régimen ordinario. No obstante, ello conlleva que determinados grupos de personas presas suelen quedar al margen de este tipo de estudios, como las que están en hospitales penitenciarios o incluso las mujeres, pues al no encontrarse en todos los centros penitenciarios generalmente resulta necesario "ir a buscarlas".

\subsection{Cuestiones éticas}

Por último, existen algunas cuestiones éticas a tener en cuenta tanto en el diseño de la investigación como en el trabajo de campo. Gran parte de ellas tienen que ver con el hecho de que las prisiones son contextos donde existen unas importantes relaciones de poder que hacen que las personas presas sean especialmente susceptibles a que sus derechos sean vulnerados. La falta de autonomía, el miedo y la desconfianza forman parte de la vida diaria de la mayoría de personas presas, y debemos tenerlo presente en varios sentidos.

En primer lugar, este contexto debería llevar a plantearnos: ¿pueden los presos rechazar libremente la encuesta? Es muy común que cuando hacemos estudios en prisión, los presos piensen que si se niegan a participar recibirán represalias por parte de la Administración. Es decir, pueden pensar que su negativa a ser encuestado será interpretada como una falta de colaboración y repercutirá en una mala valoración de su comportamiento.

Revista Española de Investigación Criminológica

Artículo 2, Volumen 19 (2) (2021)

https://doi.org/10.46381/reic.v19i2.515

www.criminologia.net

ISSN: 1696-9219 
En esta línea, es probable que muchos no quieran decir lo que realmente piensan por miedo a que la Administración (u otros presos o compañeros) tomen represalias contra ellos, lo cual aplica tanto para encuestas a la población presa como al personal penitenciario.

Es importante que cuando presentemos la investigación y la posibilidad de participar en la encuesta expliquemos muy bien los objetivos y condiciones del estudio, haciendo énfasis en que la participación es totalmente voluntaria y que no tendrá consecuencias si se decide no colaborar. Igualmente, debemos enfatizar que el estudio es independiente del centro penitenciario siempre que lo sea, resaltando, por ejemplo, nuestra afiliación a una universidad (Sutton, 2011), y que el personal de la prisión no tendrá acceso a las encuestas. Además, es conveniente explicar que los resultados se presentan de forma anónima, pues los datos se trabajan de forma agregada y no se identifican las respuestas de forma individual. Estas explicaciones permiten obtener un consentimiento informado, el cual debe ser firmado por parte de los participantes.

Sin embargo, con explicarlo no es suficiente, sino que como investigadores tenemos que recordar que estamos en una cierta posición de poder con respecto a la persona encuestada, y tenemos la responsabilidad de asegurarnos que efectivamente no exponemos ni a quienes rechazan ser encuestados ni a quienes acceden a serlo, especialmente si son personas presas. Esto implica, por ejemplo, ser cuidadosos con nuestros apuntes o asegurarnos de que no haya terceros escuchando las respuestas. Así, en ocasiones puede ser necesario pedir a un funcionario de vigilancia o a otro preso que, en la medida de lo posible, se aleje de la mesa donde se está realizando una encuesta determinada. No siempre tiene que ver con una cuestión de seguridad, sino de intimidad, pues este tipo de estudios suelen contener preguntas sobre momentos y aspectos personales sensibles. Del mismo modo, también hay que tomar este tipo de medidas cuando estamos haciendo una encuesta al personal penitenciario, pues también entre ellos existen relaciones de poder.

Una segunda cuestión ética es si debemos retribuir a las personas participantes para compensar el tiempo dedicado al estudio. Por una parte, se considera que remunerar la participación puede tener un efecto selección, de manera que solo acepten participar quienes necesiten el dinero, con el riesgo de que, al no tener una motivación intrínseca para colaborar,

Revista Española de Investigación Criminológica

Artículo 2, Volumen 19 (2) (2021)

https://doi.org/10.46381/reic.v19i2.515

www.criminologia.net

ISSN: 1696-9219 
contesten el cuestionario sin prestar suficiente atención. Por otra parte, si no retribuimos la participación puede parecer que nos estamos aprovechando de ellos. Además, el hecho de que haya una motivación económica no implica necesariamente que no haya un interés en colaborar con el estudio. Este es un extenso debate en las ciencias sociales (p. ej., Field et al. 2019) y, en función de la disciplina y del contexto geográfico, suele haber posiciones mayoritarias diferentes. En todo caso, es importante que los investigadores se planteen las implicaciones de cada opción y valoren las circunstancias, pues además de las cuestiones éticas pueden interferir otros factores, como el presupuesto. En la misma línea, independientemente de si retribuimos económicamente o no la participación, es importante dejar claro a los participantes que su colaboración en la encuesta no va a tener beneficios para su condena.

\section{Reflexiones finales: La investigación criminológica (cuantitativa) en prisión}

En este artículo hemos presentado las fuentes de datos cuantitativos para la investigación penitenciaria en España, centrándonos tanto en la información publicada y disponible como en las posibilidades de acceso para la obtención de datos adicionales, oficiales y no oficiales, mediante los portales de transparencia y la investigación empírica en prisión.

Varios trabajos han puesto de manifiesto la dificultad para acceder a la información sobre la prisión que ha existido tradicionalmente y, sobre todo, para realizar investigaciones empíricas en centros penitenciarios (véase González, 2012). El acceso a la información y a las prisiones parece haber mejorado, tal y como evidencia la proliferación de trabajos académicos publicados en los últimos años que se basan tanto en datos oficiales obtenidos mediante los portales de transparencia como a partir de investigaciones empíricas realizadas directamente en los centros penitenciarios. Probablemente, la expansión de la Criminología en nuestro país ha contribuido de forma positiva a avanzar hacia la normalización de la investigación en las prisiones.

Sin embargo, y como hemos visto a lo largo de este artículo, todavía existen numerosos problemas relacionados con el acceso a la información sobre la práctica penitenciaria, desde cuestiones técnicas como la manejabilidad de algunas bases de datos, a

Revista Española de Investigación Criminológica

Artículo 2, Volumen 19 (2) (2021)

https://doi.org/10.46381/reic.v19i2.515

www.criminologia.net

ISSN: 1696-9219 
cuestiones de fondo como la reticencia a proporcionar cierta información o a participar en las investigaciones. Por este motivo, finalizamos este artículo con algunas recomendaciones.

En primer lugar, hemos señalado limitaciones de contenido y manejabilidad en los datos oficiales publicados. En el caso de la SGIP, sería recomendable enriquecer el portal estadístico con la información contenida en los Informes Generales e, idealmente, permitir la selección de las variables que se desean consultar, incluidos los años, de forma similar a los portales del INE o Eurostat. Además, deberían definirse con precisión las categorías utilizadas, y las páginas con los datos publicados de cada Administración deberían proporcionar un correo electrónico o teléfono de contacto mediante los cuales puedan plantearse dudas.

En segundo lugar, la falta de datos desagregados por persona reclusa y/o por centro penitenciario sobre las características personales y penitenciarias de las personas presas, de su personal o del funcionamiento de la prisión dificulta profundizar en la investigación criminológica de la prisión y realizar análisis estadísticos de mayor complejidad (p. ej., en la línea de Caravaca et al., 2020). Para avanzar en esta dirección, sugerimos que la SGIP siga la buena práctica del CEJFE y proporcione en acceso abierto las bases de datos elaboradas en investigaciones llevadas a cabo desde la propia Administración, como la Encuesta sobre Salud y Consumo de Drogas en Internados en Instituciones Penitenciarias (2006, 2011, 2016) o la Evaluación del riesgo de reincidencia delictiva (2012).

En tercer lugar, es preciso garantizar una mayor transparencia y publicidad de la Administración penitenciaria respecto a la información contenida en sus sistemas informáticos penitenciarios para facilitar que los investigadores puedan realizar solicitudes mediante el portal de transparencia y construir sus propias bases de datos. Por ello recomendamos que las Administraciones publiquen un documento que especifique el tipo de información y las variables de las que disponen.

Por último, en relación con las investigaciones empíricas, sería deseable que la Administración catalana publique una Instrucción con las indicaciones, requisitos y criterios de valoración para solicitar el permiso para llevar a cabo investigaciones en el ámbito penitenciario. Asimismo, sería conveniente que tanto la AGE como Cataluña garanticen que

Revista Española de Investigación Criminológica

Artículo 2, Volumen 19 (2) (2021)

https://doi.org/10.46381/reic.v19i2.515

www.criminologia.net

ISSN: 1696-9219 
todos los centros penitenciarios cuenten con protocolos para el desarrollo de las investigaciones. Es recomendable que estos protocolos sean elaborados con la colaboración de personas que hayan realizado investigaciones en el ámbito penitenciario (para que puedan recoger sus experiencias y necesidades) y prevean la devolución por parte de los investigadores de los principales hallazgos del estudio realizado, pues ello contribuiría a comprender la importancia de la investigación criminológica y mejoraría la transferencia del conocimiento y la transformación del mismo en propuestas prácticas de mejora.

\section{Referencias}

Aebi, M. \& Tiago, M. (2020). SPACE I - 2019 - Council of Europe Annual Penal Statistics: Prison populations. Council of Europe.

Arocena, G. (1993). Vivencias de los/as funcionarios/as penitenciarios/as. Eguzkilore, (7), $157-164$.

Barquín, J., Cano, M. Á. \& Calvo, M. Á. (2019). Treatment, reintegration, and quality of prison life: Perception by inmates. International Journal of Offender Therapy and Comparative Criminology, 63(13), 2291-2317. https://doi.org/10.1177/0306624X19851669

Batlle, A. (2020). Régimen disciplinario y mujeres presas. Análisis criminológico con perspectiva de género. Tesis doctoral, Universidad Pompeu Fabra.

Beyens, K., Kennes, P., Snacken, S. \& Tournel, H. (2015). The craft of doing qualitative research in prisons. International Journal for Crime, Justice and Social Democracy, 4(1), 66-78. https://doi.org/10.5204/ijcjsd.v4i1.207

Caravaca, F., Ignatyev, Y. \& Mundt, A. (2020). The revolving prison door: Factors associated with repeat incarcerations. Journal of Forensic and Legal Medicine, 72, 1-6. https://doi.org/10.1016/j.jflm.2020.101947

Cid, J. (2020). El futuro de la prisión en España. Revista Española de Investigación Criminológica, 18, 1-32. https://doi.org/10.46381/reic.v18i0.285

Cid, J., Pedrosa, A., Ibàñez, A. \& Martí, J. (2021). Does the experience of imprisonment affect optimism about reentry? The Prison Journal, 101(1), 80-101. https://doi.org/10.1177/0032885520978476

Cuaresma, D. \& Nicolás, L. (2008). Actituds professionals dels funcionaris penitenciaris. $L$ 'efecte de la formació inicial. CEJFE.

Cutiño, S. (2015). Clasificación en tercer grado y régimen abierto en el sistema penitenciario español. Revista Penal, 36, 61-84.

Field, C., Archer, V. \& Bowman, J. (2019). Twenty years in prison: Reflections on conducting research in correctional environments. The Prison Journal, 99(2), 135149. https://doi.org/10.1177/0032885519825489

Gallego, M., Cabrera, P., Ríos, J. \& Segovia, J. L. (2010). Andar $1 \mathrm{~km}$ en línea recta. Universidad Pontificia Comillas.

Revista Española de Investigación Criminológica

Artículo 2, Volumen 19 (2) (2021)

https://doi.org/10.46381/reic.v19i2.515

www.criminologia.net

ISSN: 1696-9219 
García-España, E. (2012). Las otras poblaciones presas: Mujeres y extranjeros. Revista de Derecho Penal y Criminología, 7, 407-422.

González, I. (2012). La cárcel en España: mediciones y condiciones del encarcelamiento en el siglo XXI. Revista de Derecho Penal y Criminología, 8, 351-402.

Grant, R. \& Sugarman, J. (2004). Ethics in human subjects research: Do incentives matter? Journal of Medicine and Philosophy, 29, 717-738. https://doi.org/10.1080/03605310490883046

Güerri, C., Martí, M. \& Pedrosa, A. (2021). Abriendo ventanas virtuales en los muros de la prisión. IDP: Revista d'Internet, Dret $i$ Política, 32, 1-16. https://doi.org/10.7238/idp.v0i32.375209

Pozo, F., Navarro, L., Nakahira, M. \& Cutiño, S. (2020). El desempeño relacional de la prisión. La valoración de los presos del trato y las relaciones con funcionarios de vigilancia y personal de tratamiento. Revista Española de Investigación Criminológica, 18(1), 1-29. https://doi.org/10.46381/reic.v18i0.263

Reiter, K. (2014). Making windows in walls: Strategies for prison research. Qualitative Inquiry, 20, 417-428. http://dx.doi.org/10.1177/1077800413515831

Ríos, J. \& Cabrera, P. (1998). Mil voces presas. Universidad Pontificia de Comillas.

Rodríguez, J., Larrauri, E. \& Güerri, C. (2018). Percepción de la calidad de vida en prisión. La importancia de una buena organización y un trato digno. Revista Internacional Sociología, 76(2). https://doi.org/10.3989/ris.2018.76.2.16.159

Sutton, J. (2011). An ethnographic account of doing survey research in prison. Qualitative Sociology Review, 7(2), 45-63. 


\section{Financiamiento}

Los autores no han contado con financiación para la realización del presente trabajo.

Marta Martí es Doctora en Derecho (Criminología) por la Universitat Pompeu Fabra. Actualmente es profesora colaboradora de la Universitat Oberta de Catalunya y consultora de investigación en criminología. Sus temas de interés son el sistema de penas, las prisiones y el análisis de la delincuencia y el sistema penal desde una perspectiva de género.

https://orcid.org/0000-0001-6666-9039

Cristina Güerri es Doctora en Derecho (Criminología) por la Universitat Pompeu Fabra. Actualmente es Investigadora Posdoctoral Juan de la Cierva-Formación en el Instituto Andaluz Interuniversitario de Criminología de la Universidad de Málaga y colaboradora del Grupo de Investigación UPF en Criminología y Sistema Penal. Anteriormente ha sido Europaeum Scholar (2018-2019) e Investigadora Predoctoral FPU en la Universitat Pompeu Fabra (2015-2019). Sus líneas de investigación exploran cuestiones diversas relacionadas con el sistema penitenciario español, como las condiciones de vida en prisión, el rol de los funcionarios de interior o la situación de las personas extranjeras.

https://orcid.org/0000-0002-4382-040X

Albert Pedrosa es Doctor en Derecho (Criminología) por la Universitat Autònoma de Barcelona. Actualmente se encuentra vinculado al grupo de investigación en Desistimiento del Delito y Políticas de Reinserción de la UAB. Sus temas de interés son el estudio del uso de la prisión, la situación de las familias de personas encarceladas y el control penal sobre colectivos en riesgo de exclusión.

https://orcid.org/0000-0002-3533-7282 


\section{Anexos}

Tabla 1

Información disponible en los Informes Generales de Instituciones Penitenciarias

\begin{tabular}{|c|c|}
\hline Categorías & Ejemplos de la información que se proporciona \\
\hline Clasificación penitenciaria & $\begin{array}{l}\text { Clasificación inicial; aplicación del principio de flexibilidad; entre } \\
\text { otros. }\end{array}$ \\
\hline $\begin{array}{l}\text { Permisos de salida y salidas } \\
\text { programadas }\end{array}$ & $\begin{array}{l}\text { Permisos de salida concedidos y núm. de internos con permisos; salidas } \\
\text { programadas organizadas y núm. de internos que las han disfrutado; } \\
\text { entre otros. }\end{array}$ \\
\hline Programas de tratamiento & $\begin{array}{l}\text { Núm. de internos cursando los distintos tipos de programas de } \\
\text { tratamiento en los centros; tratamiento extrapenitenciario de } \\
\text { drogodependientes... }\end{array}$ \\
\hline $\begin{array}{l}\text { Programas formativos, } \\
\text { ocupacionales, culturales y } \\
\text { deportivos }\end{array}$ & $\begin{array}{l}\text { Número de internos en programa de alfabetización; educación } \\
\text { secundaria para personas adultas; animación a la lectura o ciberaulas; } \\
\text { número de campeonatos de deportes y certámenes culturales } \\
\text { organizados; entre otros. }\end{array}$ \\
\hline $\begin{array}{l}\text { Trabajo remunerado y formación } \\
\text { profesional }\end{array}$ & Cocina; economato; manipulados; entre otros. \\
\hline Régimen abierto & $\begin{array}{l}\text { Núm. de internos en régimen abierto según lugar de cumplimiento; } \\
\text { núm. de internos cursando los distintos programas de tratamiento } \\
\text { específicos de medio abierto y núm. de internos del } 86.4 \mathrm{CP} \text { en } \\
\text { seguimiento mediante control telemático. }\end{array}$ \\
\hline Extranjería & $\begin{array}{l}\text { Población según situación procesal-penal; centros penitenciarios con } \\
\text { mayor proporción de extranjeros; tipología de delictiva y forma de } \\
\text { excarcelación. }\end{array}$ \\
\hline $\begin{array}{l}\text { Ancianidad en el medio } \\
\text { penitenciario (mayores de } 70 \text { años) }\end{array}$ & $\begin{array}{l}\text { Perfil sociodemográfico; clasificación penitenciaria; tipología delictiva, } \\
\text { contacto con familiares o allegados; disfrute de permisos; ingresos } \\
\text { económicos; tipo de módulo donde se ubican; dependencia mental o } \\
\text { física. }\end{array}$ \\
\hline Sanidad & $\begin{array}{l}\text { Datos epidemiológicos (drogodependencias, salud mental, VIH, } \\
\text { hepatitis C, mortalidad...); cifras sobre la atención sanitaria } \\
\text { proporcionada a los reclusos (penitenciaria y extrapenitenciaria) e } \\
\text { internos tratados en programas de drogodependencias o de atención } \\
\text { integral al enfermo mental. }\end{array}$ \\
\hline Personal penitenciario & $\begin{array}{l}\text { Volumen de personal según escala funcionarial; número de plazas } \\
\text { públicas convocadas y cursos de formación y número de participantes. }\end{array}$ \\
\hline
\end{tabular}

Fuente: Elaboración Propia 


\section{Tabla 2}

Información disponible en los Descriptors Estadístics de Serveis Penitenciaris (Cataluña)

\begin{tabular}{|c|c|}
\hline Categorías & Información disponible \\
\hline $\begin{array}{l}\text { Evolución de la población } \\
\text { penitenciaria }\end{array}$ & $\begin{array}{l}\text { Población en prisión a último día del mes; internos diferentes; previsión } \\
\text { de crecimiento; tasa por } 100.000 \text { habitantes; altas desde libertad y bajas } \\
\text { por libertad. }\end{array}$ \\
\hline $\begin{array}{l}\text { Tiempo de estancia en prisión y } \\
\text { condena impuesta }\end{array}$ & $\begin{array}{l}\text { Tiempo de estancia en prisión; tiempo total de condena impuesta (media } \\
\text { y total); internos que han cumplido la } 1 / 2 \text { de la pena; duración de la pena } \\
\text { de las nuevas altas. }\end{array}$ \\
\hline Descriptores procesales-penales & Penados y preventivos; reincidencia (internos sin condena previa). \\
\hline Actividad delictiva & Tipología del delito principal. \\
\hline Descriptores sociodemográficos & Internos según género; edad y nacionalidad. \\
\hline Mujeres & $\begin{array}{l}\text { Situación procesal-penal; internas diferentes; altas y bajas; tipología } \\
\text { delictiva; tiempo total de condena impuesto; tiempo medio de estancia } \\
\text { en prisión; edad; nacionalidad; clasificación en grados de tratamiento; } \\
\text { permisos; expedientes disciplinarios y maternidad. }\end{array}$ \\
\hline Jóvenes & $\begin{array}{l}\text { Situación procesal-penal; jóvenes diferentes; altas y bajas; tipología } \\
\text { delictiva; tiempo total de condena impuesto; tiempo medio de estancia } \\
\text { en prisión; edad; nacionalidad; clasificación en grados de tratamiento. }\end{array}$ \\
\hline Extranjería & $\begin{array}{l}\text { Situación procesal-penal; jóvenes diferentes; altas y bajas; tipología } \\
\text { delictiva; tiempo total de condena impuesto; tiempo medio de estancia } \\
\text { en prisión; edad; nacionalidad y región de procedencia; régimen de vida; } \\
\text { permisos; expedientes disciplinarios. }\end{array}$ \\
\hline Reeducación y reinserción social & $\begin{array}{l}\text { Clasificación en grado de tratamiento; libertad condicional; trabajo } \\
\text { productivo y formación ocupacional; programas de tratamiento; } \\
\text { programas formativos, culturales y deportivos. }\end{array}$ \\
\hline Permisos & $\begin{array}{l}\text { Disfrute de permisos; núm. de internos que disfrutan por primera vez de } \\
\text { un permiso; salidas programadas; incumplimiento del permiso. }\end{array}$ \\
\hline Incidencias & $\begin{array}{l}\text { Núm. de incidentes y núm. de internos diferentes para lesiones leves, } \\
\text { lesiones graves, autolesiones y evasiones consumadas; expedientes } \\
\text { disciplinarios incoados según gravedad y según sanción impuesta. }\end{array}$ \\
\hline Descriptores sanitarios & $\begin{array}{l}\text { Datos epidemiológicos (VIH, Hepatitis C...); libertades condicionales } \\
\text { anticipadas y defunciones según causa. }\end{array}$ \\
\hline Gestión & Traslados. \\
\hline Personal & Plantilla de los servicios penitenciarios. \\
\hline
\end{tabular}

Fuente: Elaboración propia.

Revista Española de Investigación Criminológica

Artículo 2, Volumen 19 (2) (2021)

https://doi.org/10.46381/reic.v19i2.515

WWW.criminologia.net

ISSN: 1696-9219 